\title{
Two new species of harvestmen (Opiliones, Eupnoi, Neopilionidae) from Waitomo, New Zealand
}

\author{
Christopher K. Taylor', Anna Probert ${ }^{2}$ \\ I Dept of Environment and Agriculture, Curtin University, GPO Box U1987, Perth, WA 6845, Australia \\ 2 School of Biological Sciences, University of Auckland, Private Bag 92019, Auckland Mail Centre, Auckland \\ 1142, New Zealand
}

Corresponding author: Christopher K. Taylor(chris.taylor@curtin.edu.au)

Academic editor: Adriano Kury | Received 12 March 2014 | Accepted 6 August 2014 | Published 14 August 2014

http://zoobank.org/0A3E6FDD-E27D-49DF-92FD-04D0987C9CCO

Citation: Taylor CK, Probert A (2014) Two new species of harvestmen (Opiliones, Eupnoi, Neopilionidae) from Waitomo, New Zealand. ZooKeys 434: 37-45. doi: 10.3897/zookeys.434.7486

\begin{abstract}
Two new species of harvestman (Opiliones: Neopilionidae: Enantiobuninae) are described from the Waitomo region of the North Island, New Zealand, Forsteropsalis bona sp. n. and F. photophaga sp. n. Both have been collected within caves in the region, where predation on glow-worms Arachnocampa luminosa has been previously recorded for one or both species (misidentified as Megalopsalis tumida). However, both are regarded as troglophiles rather than strict troglobites due to the presence of specimens outside the cave systems, and the absence of troglobitic adaptations. Megalopsalis tumida (Forster, 1944) is identified as a junior synonym of Forsteropsalis fabulosa (Phillipps \& Grimmett, 1932).
\end{abstract}

\section{Keywords}

Taxonomy, arachnids, cave biota

\section{Introduction}

The Waitomo region of the North Island, New Zealand, has become internationally renowned as a tourist attraction owing to its extensive cave systems. The primary reason for their fame is their large population of glow-worms Arachnocampa luminosa 
(Keroplatidae). These luminescent fly larvae construct silken nests on the roof of the cave from which they hang sticky threads to capture flying insects attracted to their light (Richards 1960). They are themselves predated upon by harvestmen (Opiliones), which are able to avoid entanglement by the glow-worms' threads and pull the larvae from their nests (Richards 1960; Meyer-Rochow and Liddle 1988).

Richards (1960) recorded two species of harvestmen feeding on glow-worms at Waitomo. One, Hendea myersi cavernicola Forster, 1954 (Triaenonychidae), was originally described from Waitomo. The second species was identified by both Richards (1960) and Meyer-Rochow and Liddle (1988) as Megalopsalis tumida (Forster, 1944) (Neopilionidae). Richards (1960) recorded this species feeding only on mature glow-worm gnats; Meyer-Rochow and Liddle (1988) recorded it also feeding on pupae and late-instar larvae. Megalopsalis tumida is a junior synonym of Forsteropsalis fabulosa (Phillipps \& Grimmett, 1932) (see below), and was originally described from near Wellington. Examination of specimens collected from caves in the Waitomo region revealed the presence of two species of Neopilionidae, both of them described as new below. Which of these was the species mentioned by Richards (1960) and Meyer-Rochow and Liddle (1988) is unknown. Forsteropsalis bona sp. n. is the more similar to $F$. fabulosa, but a photograph of 'Megalopsalis tumida' in Meyer-Rochow and Liddle (1988) may show F. photophaga sp. n. It is not impossible that the two were confused.

While Meyer-Rochow and Liddle (1988) regarded Hendea myersi cavernicola as a true troglobite, and did not find it outside the cave entrance, the collection of small numbers of ' $M$. tumida' outside the cave led them to regard it as troglophilic rather than troglobitic. Similar habits were inferred by Taylor (2013) for Megalopsalis suffugiens Taylor, 2013, described from caves in Western Australia. Further epigean specimens are recorded herein for Forsteropsalis bona, while specimens collected in the cave were only a short distance from the entrance. Forsteropsalis photophaga has not yet been conclusively recorded outside the caves, but troglophily is also suggested for this species by the absence of strong adaptations for troglobitism.

\section{Methods}

Specimens were sourced from the collection of Te Papa Tongarewa, Wellington, New Zealand (MONZ) or collected by hand by A. Probert and associates. Specimens collected by A. Probert will be deposited at the New Zealand Arthropod Collection, Landcare Research, Auckland, New Zealand (NZAC). All specimens are assigned to the area code WO (Waikato) by the system established by Crosby et al. (1998). Photographs and measurements were taken using a Nikon SMZ1500 stereo microscope and the NIS-Elements D 4.00 .03 programme, and a Leica DM2500 compound microscope. Measurements are given in millimetres $(\mathrm{mm})$. Coloration is described as in alcohol (live coloration is given in parentheses). 


\section{Taxonomic descriptions}

\section{Forsteropsalis bona sp. $\mathbf{n}$.}

http://zoobank.org/32F7E0A3-1CE0-41EF-B7AA-48DDAE2A529A

Figure 1

Holotype male. WO. Lucky Strike Cave, Te Kuiti, on wall near entrance, 14 Feb 1959, K. A. J. Wise (MONZ).

Paratypes. WO. 2 males, Waitomo Valley, in stream crevice outside cave entrance (shady), specimens intertwined and sluggish, 30 Mar 1959, L. G. Watson (MONZ); 1 male, Weir Cave, Stubbs Farm, Waitomo, ca. $2 \mathrm{~m}$ from cave entrance within a $15 \mathrm{~cm}$ radius of Arachnocampa luminosa larvae, 23 Aug 2010, A. Probert (NZAC).

Etymology. From the Latin bonus, good, in contrast to the related Forsteropsalis fabulosa.

Male (n=4). Total body length 4.8-6.6; prosoma length 2.5-2.8, width 4.0-4.2. Prosoma (including ocularium) unarmed (Fig. 1A); ground colour in alcohol orangebrown with longitudinal yellow stripes on either side of ocularium (live coloration very dark brown [almost black] with orange-yellow stripes; appendages also black). Ozopores elongate, with small flanking lobes. Opisthosoma grey-yellow. Mouthparts cream-coloured; medial side of pedipalpal coxa with dense array of sharp denticles; cervix unarmed. Coxae yellow. Chelicerae (Fig. 1B): Segment I length 6.2-8.4; segment II 9.4-10.4. Elongate; segment I orange with lighter yellow patch at distal end, segment II dark orange-brown. Segment I denticulate, with denticles concentrated along dorsal, proventral and retroventral margins. Segment II massively inflated, evenly denticulate. Cheliceral fingers elongate, widely bowed apart; setae present on distal half of mobile finger. Pedipalps: Femur length 5.4-5.7; patella 2.2-2.4; tibia 2.8-3.1; tarsus 5.8-6.5. Distinctly elongate, yellow. Femur dorsally denticulate on proximal two-thirds; remainder of pedipalp unarmed. Setae sparse except for small concentration at prodistal end of patella; microtrichia present on tarsus and distal half of tibia; prodorsal end of patella with distinct protrusion but without definite finger-like apophysis (Fig. 1C). Tarsal claw without ventral tooth-row. Legs: Legs I femur length 8.6-9.9, patella 1.9-2.5, tibia 8.3-9.8; leg II femur 14.3-17.2, patella 2.2-2.8, tibia 14.4-17.8; leg III femur 7.5-8.7, patella 1.7-2.3, tibia 5.3-8.2; leg IV femur 8.5-10.7, patella 1.8-2.7, tibia $10.2-10.8$. Femora sparsely denticulate, particularly in proximal half; remainder of legs unarmed. Distitarsus I with strong ventral tooth at distal end of each of first five or six pseudosegments (Fig. 1D). Tibia II with nine to fifteen pseudosegments; tibia IV with two pseudosegments. Penis (Fig. 1E-F): Shaft subquadrate; tendon long. Bristle groups relatively long, posterior bristle group with longest bristles reaching dorsal margin in lateral view. Glans short, subtriangular in ventral view, narrowing rapidly in lateral view.

Comments. Females of this species are currently unknown. Forsteropsalis bona can be distinguished from most other Forsteropsalis species by its unarmed prosoma 

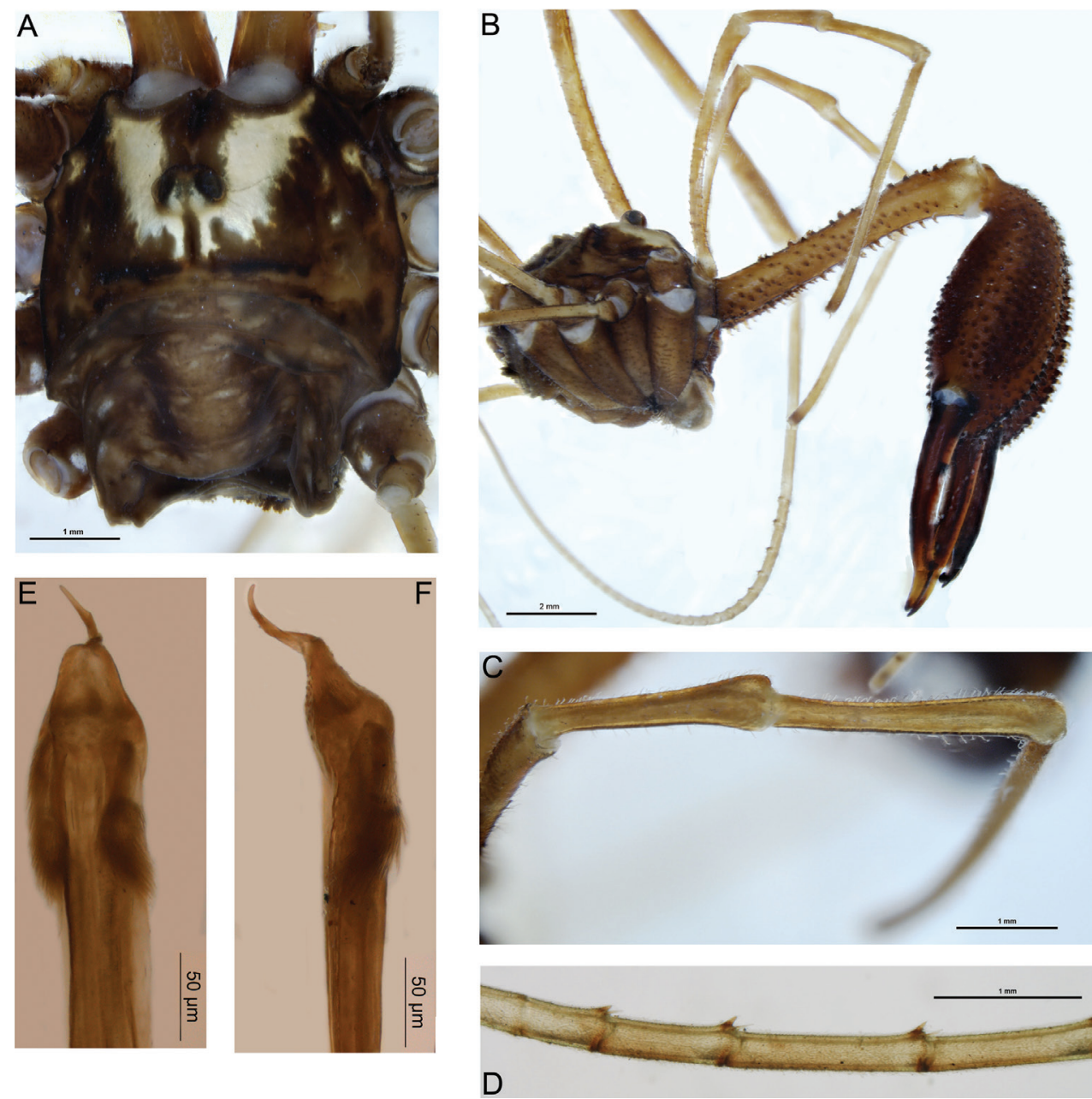

Figure I. Forsteropsalis bona sp. n. A dorsal view of body, holotype B lateral view of body, pedipalps and chelicerae, holotype $\mathbf{C}$ dorsal view of right pedipalpal patella and tibia, holotype $\mathbf{D}$ proximal pseudosegments of right distitarsus I (venter upwards), holotype, showing ventrodistal teeth $\mathbf{E}$ penis, ventral view, specimen from Waitomo Valley $\mathbf{F}$ penis, right lateral view, specimen from Waitomo Valley.

and enormous, sub-globose cheliceral segment II with widely bowed cheliceral fingers (Taylor 2011). In these features it strongly resembles F. fabulosa, and would key out to either F. fabulosa or F. tumida in the key to Forsteropsalis species provided by Taylor (2011). These two species are synonymised below. Forsteropsalis bona can be distinguished from F. fabulosa by the form of the pedipalpal patella: F. fabulosa has a distinct finger-like prodistal apophysis on the patella (Phillipps and Grimmett 1932: Fig. C p. 732), while the patellar apophysis is almost absent in F. bona (Fig. 1C). Forsteropsalis fabulosa also has denticles both dorsally and ventrally on the pedipalpal femur, while F. bona has denticles dorsally only. 
An interesting feature of Forsteropsalis bona is the presence of a strong ventrodistal tooth on the end of each of the proximal pseudosegments of the distitarsus. This tooth sits between the two spinose setae generally present on each tarsal pseudosegment in all Enantiobuninae (Fig. 1D). Such a feature has not previously been recorded for this subfamily, though it is also present in F. fabulosa (specimens from MONZ, details given in Taylor 2011). This may represent a distinct synapomorphy of these two species.

The glans of both Forsteropsalis fabulosa (Taylor 2011) and F. bona is relatively short compared to other Forsteropsalis species, and converges in shape on that of the Australian genus Megalopsalis (Taylor 2011, 2013). Nevertheless, the remaining features of these two species support a direct relationship with other New Zealand species of Pantopsalis and Forsteropsalis, and with Forsteropsalis in particular. These features include dorsal papillae on the glans (Taylor 2011), setae on the mobile finger of the chelicera (absent in Megalopsalis except M. caeruleomontium; Taylor 2011, 2013), and an array of denticles on the medial side of the pedipalpal coxa (Fig. 3A; Taylor 2011).

\section{Forsteropsalis fabulosa (Phillipps \& Grimmett, 1932)}

Macropsalis fabulosa Phillipps \& Grimmett, 1932: 731-733, fig. p. 732.

Megalopsalis fabulosa (Phillipps \& Grimmett) - Forster 1944: 186-187, figs 10-11 (misidentification of Forsteropsalis inconstans).

Megalopsalis tumida Forster 1944: 188-189, figs 4-6 syn. n.

Forsteropsalis fabulosa (Phillipps \& Grimmett) - Taylor 2011: 51, figs 99-101, 2012: 49. Forsteropsalis tumida (Forster) - Taylor 2011: 60-61, figs 124-127.

Comments. Forsteropsalis fabulosa and F. tumida were distinguished in Taylor (2011) solely by the degree of dilation of the second cheliceral segment, with the latter supposedly more inflated in F. tumida than in F. fabulosa. A number of species of Forsteropsalis and its sister genus Pantopsalis are now known to vary in cheliceral dilation (Taylor 2004, 2011, 2013, and see Forsteropsalis photophaga below). Forsteropsalis fabulosa and F. tumida were both described from the Wellington district, and there seems to no longer be any justification for separating them as different species. Forsteropsalis tumida is therefore regarded herein as a junior synonym of $F$. fabulosa (syn. n.).

\section{Forsteropsalis photophaga sp. n.}

http://zoobank.org/633102AB-D0FD-4F91-8A38-CFDF1ECDF08F

Figure 2

Holotype male. WO. Waitomo, Gardners Gut Cave System, 200 yards from Zweihöllen entrance, 25 June 1977, W. L. Blundell (MONZ).

Paratypes. WO. 1 male, Giants Cavern, Hollow Hill Cave, Te Kuiti, in 'Crows Nest', 60-70 ft high, 12 January 1958, coll. R. W. Taylor (MONZ); 1 male, Aussie 

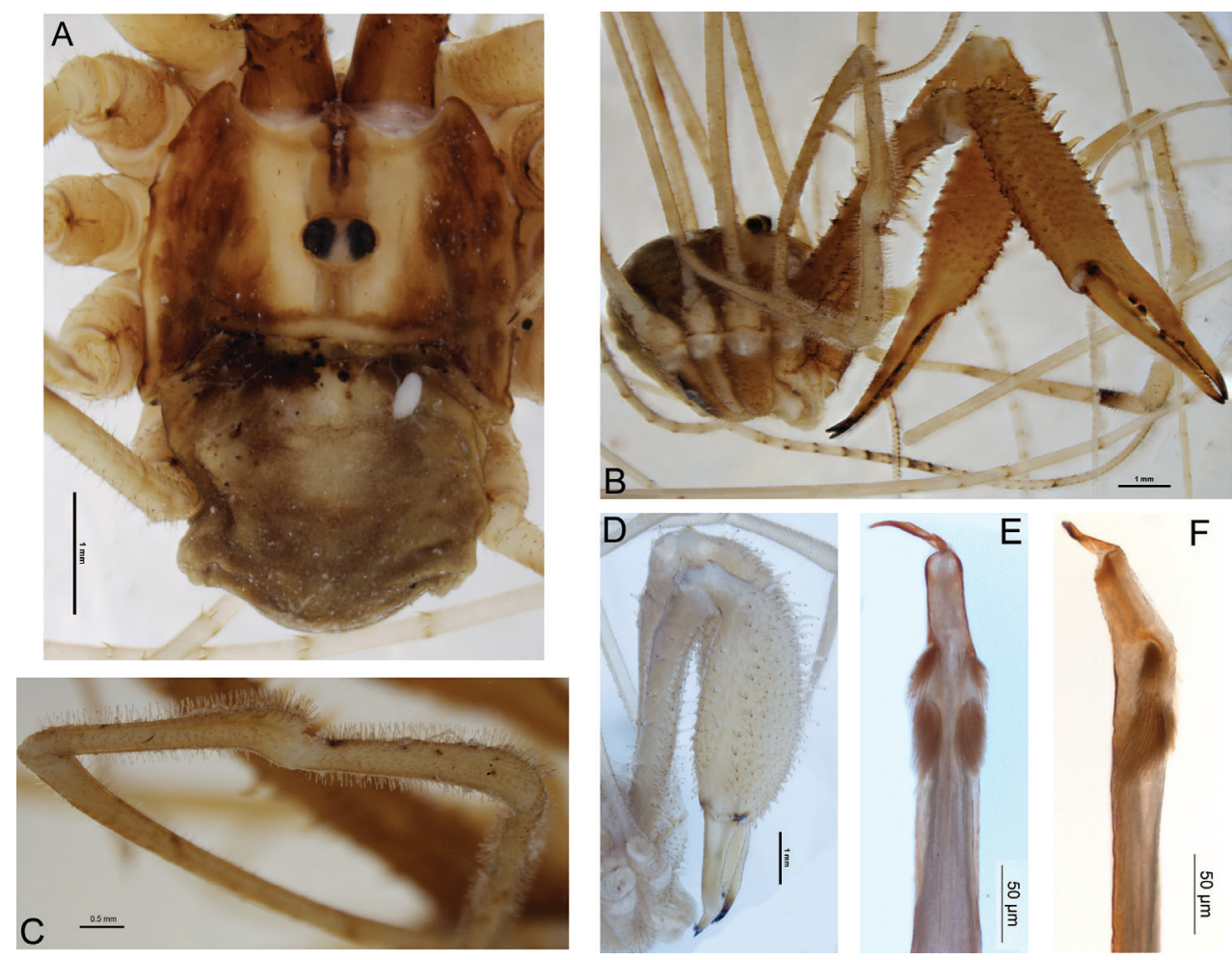

Figure 2. Forsteropsalis photophaga sp. n. A dorsal view of body, holotype, with parasitic mite attached B anterolateral view of body, pedipalps and chelicerae, holotype $\mathbf{C}$ dorsal view of right pedipalpal patella and tibia, holotype $\mathbf{D}$ anterolateral view of chelicerae of specimen from Aussie Cave, showing more inflated chelicerae $\mathbf{E}$ penis, ventral view, holotype $\mathbf{F}$ penis, right lateral view, holotype.

Cave, Taumatamaire Rd, Waitomo County, 50 ft, 16 May 1966, K. A. J. Wise (MONZ); 2 males, Stubbs Farm, Waitomo, on rocky cave substrate, February 2013, G. Holwell et al. (NZAC); 2 males, Mangapohue Cave, Stubbs Farm, Waitomo, on rocky cave substrate, 21 Oct 2013, A. Probert \& D. Townsend (NZAC).

Etymology. From the Greek phos, light, and phagein, to eat, in reference to this species' predation of the glow-worm Arachnocampa luminosa.

Male (n=7). Total body length 3.5-6.1; prosoma length 1.9-2.1, width 2.5-3.9. Prosoma (including ocularium) unarmed except for few black setae (Fig. 2A); ground colour orange-brown with longitudinal yellow stripes on either side of ocularium (live colouration light to mid-brown with pale yellow stripes). Ozopores elongate, with small flanking lobes. Opisthosoma grey-brown. Mouthparts cream-coloured; medial side of pedipalpal coxa with array of sharp denticles; cervix with single pair of denticles laterally. Coxa I orange; remaining coxae and venter of opisthosoma yellow. Chelicerae (Fig. 2B, D): Segment I length 3.4-6.5, segment II 4.9-9.1. Elongate; orange except for lighter yellow patch at distal end of first segment. First segment dorsally with scattered denticles, becoming more elongate retrolaterally, ventrally with longitudinal prolateral 
and retrolateral rows of elongate denticles and some scattered median denticles proximally. Second segment mildly to notably inflated, sub-conical, evenly denticulate with longitudinal rows of more elongate denticles dorsally and retrolaterally. Cheliceral fingers elongate, slightly bowed apart; setae present along central third of mobile finger. Pedipalps: Femur length 4.6-6.5, patella 2.8-3.2, tibia 2.2-2.8, tarsus 4.8-5.7. Distinctly elongate; yellow. Median side of coxa with array of sharp denticles. Femur with few denticles dorsally in proximal half; remainder of pedipalp unarmed. Patella, tibia and proximal half of tarsus densely covered with plumose setae; microtrichia present over entirety of patella, tibia and tarsus; patella with small, rounded, prodistal apophysis (Fig. 2C). Tarsal claw without ventral tooth-row. Legs: Leg I femur length 8.1-11.0, patella 1.9-2.2, tibia 8.4-10.7; leg II femur 14.0-17.7, patella 1.9-2.5, tibia 16.0-19.0; leg III femur 7.1-9.4, patella 1.6-1.9, tibia 7.6-9.8; leg IV femur 9.0-12.2, patella 1.8-2.2, tibia 10.3-12.4. Yellow. Proximal half of femur I with few scattered dorsal denticles; remainder of legs unarmed. Tibia II with 12 pseudosegments; tibia IV with three pseudosegments. Penis (Fig. 2E-F): Shaft subquadrate; tendon long. Bristle groups relatively long, posterior bristle group with longest bristles reaching dorsal margin in lateral view. Glans relatively long, subrectangular in ventral view, remaining relatively deep to distal end but with dorsodistal end rounded.

Comments. Females of this species are currently unknown. The holotype of Forsteropsalis photophaga when first examined had a parasitic mite attached to the opisthosoma (Fig. 2A). This mite is a representative of the Microtrombidiidae, a family that has not previously been recorded as parasitic on Opiliones; a more detailed description is currently being prepared by C. Taylor.

The genera Pantopsalis and Forsteropsalis have hitherto been regarded as well distinguished by the morphology of the cheliceral fingers (crescent-shaped in Pantopsalis vs bowed in Forsteropsalis), pedipalpal patellar apophysis (hypersetose and rounded in Pantopsalis, sparsely setose and triangular in Forsteropsalis) and penile bristle groups (shorter in Pantopsalis than in Forsteropsalis) (Taylor 2004, 2011). The current species blurs this distinction: in its hypersetose and rounded pedipalpal apophysis it resembles Pantopsalis, but its elongate cheliceral fingers and penile bristle groups are more characteristic of Forsteropsalis. It also possesses an array of denticles on the medial side of the pedipalpal coxa as found in Forsteropsalis species (Fig. 3A; Taylor 2011). We therefore assign it to the latter genus herein. A hypersetose, rounded patella is also present in the female of $F$. grimmetti, though the male of that species possesses a more typical Forsteropsalis-type patella (Taylor 2011). It is possible that the hypersetose patella is in fact a symplesiomorphy of Pantopsalis and Forsteropsalis, with $F$. photophaga being a basal member of the latter genus.

Forsteropsalis photophaga can be readily distinguished from all other Neopilionidae in New Zealand by the hypertrophied denticle rows on the second cheliceral segment. The only other neopilionid with comparable chelicerae is the major male of the Tasmanian species Megalopsalis nigricans (Hickman 1957). This, however, is a much smaller species, with very different genital morphology and with small ozopores unlike those of any Forsteropsalis species (Hickman 1957, Taylor 2013). 

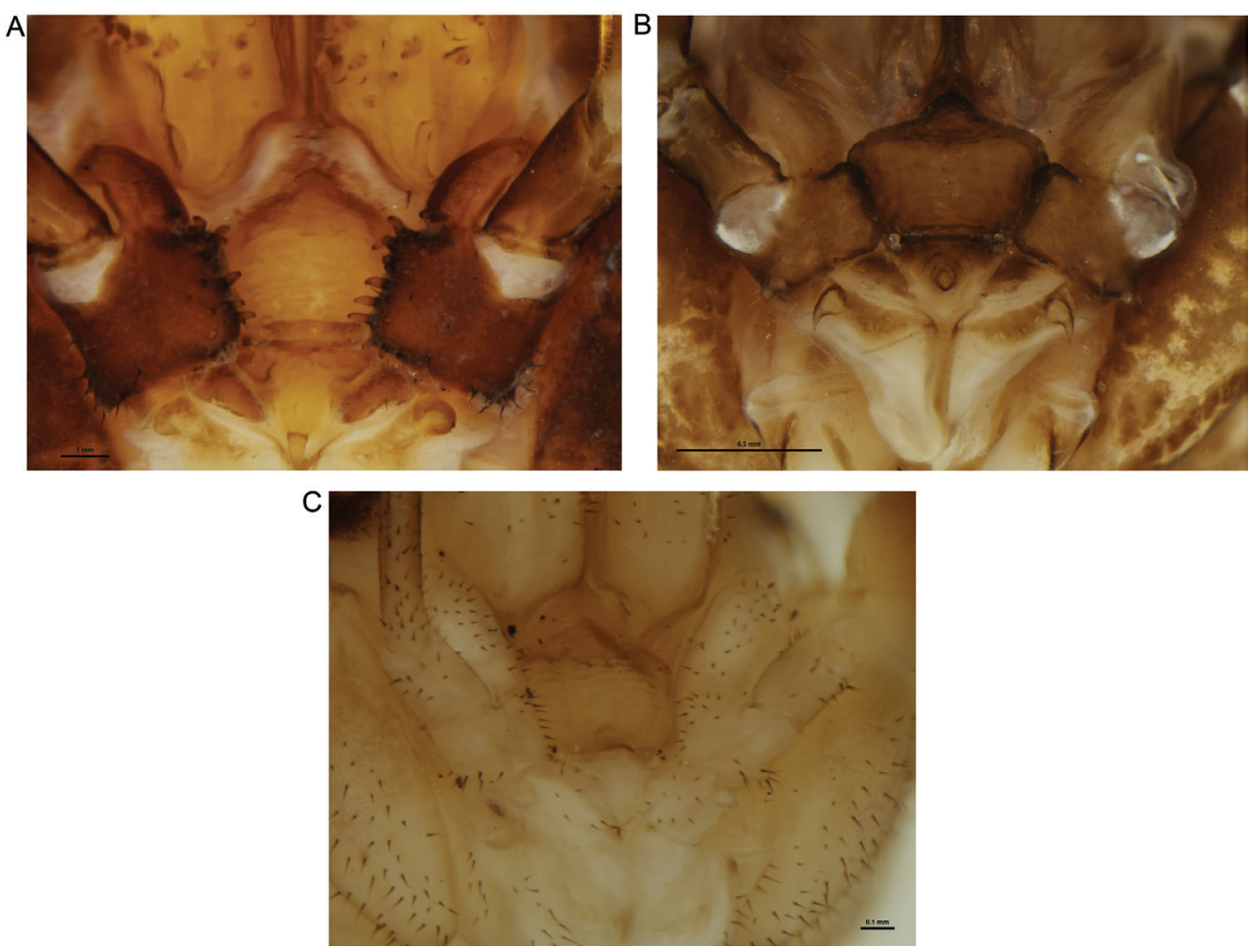

Figure 3. Mouthparts of selected New Zealand Neopilionidae, showing morphology of pedipalpal coxae. A Forsteropsalis chiltoni, with medial denticles B Pantopsalis albipalpis, with sclerotised medial flange overhanging cervix $\mathbf{C}$ Mangatangi parvum, with unarmed, simple coxae.

\section{Acknowledgements}

The authors would like to thank Phil Sirvid, Te Papa Tongarewa, for arranging the loan of specimens. Anna Probert was assisted in collecting specimens by Daniel Townsend, Greg Holwell and Christina Painting. Access to caves on Stubbs Farm was provided by Alister and Ann Stubbs. Christopher Taylor's position at Curtin University is funded by Chevron Australia.

\section{References}

Crosby TK, Dugdale JS, Watt JC (1998) Area codes for recording specimen localities in the New Zealand subregion. New Zealand Journal of Zoology 25: 175-183. doi: 10.1080/03014223.1998.9518148

Forster RR (1944) The genus Megalopsalis Roewer in New Zealand with keys to the New Zealand genera of Opiliones. Records of the Dominion Museum 1(1): 183-192.

Forster RR (1954) The New Zealand harvestmen (sub-order Laniatores). Canterbury Museum Bulletin 2: 1-329. 
Hickman VV (1957) Some Tasmanian harvestmen of the sub-order Palpatores. Papers and Proceedings of the Royal Society of Tasmania 91: 65-79.

Meyer-Rochow VB, Liddle AR (1988) Structure and function of the eyes of two species of opilionid from New Zealand glow-worm caves (Megalopsalis tumida: Palpatores, and Hendea myersi cavernicola: Laniatores). Proceedings of the Royal Society of London Series B (Biological Sciences) 233: 293-319. doi: 10.1098/rspb.1988.0023

Phillipps WJ, Grimmett RER (1932) Some new Opiliones from New Zealand. Proceedings of the Zoological Society of London 1932: 731-740.

Richards AM (1960) Observations on the New Zealand glow-worm Arachnocampa luminosa (Skuse) 1890. Transactions of the Royal Society of New Zealand 88(3): 559-574.

Taylor CK (2004) New Zealand harvestmen of the subfamily Megalopsalidinae (Opiliones: Monoscutidae) - the genus Pantopsalis. Tuhinga 15: 53-76.

Taylor CK (2011) Revision of the genus Megalopsalis (Arachnida: Opiliones: Phalangioidea) in Australia and New Zealand and implications for phalangioid classification. Zootaxa 2773: 1-65.

Taylor CK (2012) Clarification of the type status of Macropsalis fabulosa Phillipps \& Grimmett 1932. Zootaxa 3194: 49-50.

Taylor CK (2013) Further revision of the genus Megalopsalis (Opiliones, Neopilionidae), with the description of seven new species. ZooKeys 328: 59-117. doi: 10.3897/ zookeys.328.5439 